\title{
Reactions to and Desire for Prognostic Testing in Choroidal Melanoma Patients
}

\author{
Tammy M. Beran • Tara A. McCannel • \\ Annette L. Stanton - Bradley R. Straatsma • \\ Barry L. Burgess
}

Received: 23 June 2008 / Accepted: 29 January 2009 /Published online: 7 May 2009

(C) The Author(s) 2009. This article is published with open access at Springerlink.com

\begin{abstract}
To determine if choroidal melanoma patients want cytogenetic prognostic information. Ninety-nine choroidal melanoma patients completed a questionnaire regarding their opinions about receiving prognostic information. The perceived usefulness of prognostic information was evaluated in patients who had undergone cytogenetic testing. Depressive symptoms, quality of life, and interest in supportive counseling during test receipt were assessed. Ninety-seven percent of respondents reported that they would have wanted prognostic information at the time of their treatment and $98 \%$ of respondents reported that supportive counseling should be offered when prognostic information is given. Patients who had received a more favorable prognostic result were more likely to
\end{abstract}

T. M. Beran · A. L. Stanton

Department of Psychology, UCLA,

Los Angeles, CA, USA

T. M. Beran • T. A. McCannel - B. R. Straatsma • B. L. Burgess Department of Ophthalmology, UCLA,

Los Angeles, CA, USA

T. M. Beran · T. A. McCannel - B. R. Straatsma • B. L. Burgess Jules Stein Eye Institute, UCLA,

Los Angeles, CA, USA

T. A. McCannel • A. L. Stanton • B. R. Straatsma

Jonsson Comprehensive Cancer Center, UCLA,

Los Angeles, CA, USA

\author{
A. L. Stanton \\ Department of Psychiatry and Biobehavioral Sciences, UCLA, \\ Los Angeles, CA, USA \\ T. A. McCannel $(\triangle)$ \\ UCLA JSEI-Ophthalmology, \\ BOX 957000, 3-519A DSERC Bldg, \\ Los Angeles, CA 90095-7000, USA \\ e-mail: tmccannel@jsei.ucla.edu
}

endorse the usefulness of cytogenetic testing than were patients who had received a less favorable prognostic result. Psychological status did not vary significantly as a function of cytogenetic test result. Prognostic information was important to patients with choroidal melanoma, even in the absence of prophylactic measures which might improve prognosis.

Keywords Choroidal melanoma Prognostic testing · Patient preferences . Cytogenetic testing .

Psychological adjustment . Chromosome 3 - Monosomy 3 . Disomy 3

\section{Introduction}

Choroidal melanoma is the most common primary intraocular cancer in adults affecting 4 to 7 persons per million in the United States (McLaughlin et al. 2005; Scotto et al. 1976). Despite effective ocular therapies, choroidal melanoma remains a deadly cancer with $50 \%$ of patients developing systemic metastasis (Hawkins 2004; Kujala et al. 2003; Prescher et al. 1996; Tschentscher et al. 2000). Metastatic choroidal melanoma is usually fatal within 1 year and rarely responds to systemic interventions (Bedikian 2006).

In recent years, genetic markers in choroidal melanoma cells have been correlated with the risk of melanoma metastasis. For example, loss of one copy of chromosome 3 (monosomy 3), which occurs in approximately half of choroidal melanomas, is strongly associated with metastatic death (Damato et al. 2007; Prescher et al. 1996). Nearly $50 \%$ of patients with monosomy 3 develop metastasis within 5 years of ocular treatment while significantly fewer patients with two copies of chromosome 3 (disomy 3 ) 
develop metastasis (Damato et al. 2007; Prescher et al. 1996; Scholes et al. 2003; Sisley et al. 1997; White et al. 1998). The feasibility of intraoperative transscleral fine needle aspiration biopsy (FNAB) at the time of Iodine-125 plaque application has been demonstrated. Biopsy material may be analyzed for chromosome 3 status by fluorescence in-situ hybridization (FISH) and high-density mapping genome array (Midena et al. 2006; Onken et al. 2006; Shields et al. 2007a; Young et al. 2007a).

The performance of screening tests that have little influence on medical management has been considered controversial in medicine (Bird 1989). With rare exception, systemic therapy does not reduce mortality or prolong survival in patients with metastatic choroidal melanoma. Additionally, there is on-going discussion regarding the most prognostically valuable test for choroidal melanoma and whether the implementation of prophylactic chemoprevention based upon prognostic information is appropriate (Harbour 2007; Robertson 2008; Shields et al. 2008). While the scientific merits of individually varying prognostic assays in choroidal melanoma continue to be debated, the psychological implications of providing information obtained from any such prognostic test require increased attention. In the absence of effective metastatic treatment therapies, the non-medical implications of prognostication may have the most impact on patients. This is the case in Huntington's Disease, a progressive neurodegenerative condition resulting in eventual death, where atrisk individuals often cite primarily non-medical reasons (e.g., life planning, increased sense of control) for seeking genetic testing (Williams et al. 1999).

There are additional reasons to examine the psychological implications of prognostic testing in choroidal melanoma. In a review of the literature on genetic testing in cancer, Meiser (2005) cautioned against generalizing findings from one genetic testing cancer context to another as different patterns have emerged between cancers. Additionally, the vast majority of genetic testing in cancer is either predictive of the development of cancer (e.g., BRCA1/2 testing: Miki et al. 1994; Wooster et al. 1995), rather than the prognosis of an already diagnosed malignancy (Fertig and Hayes 2001) or makes use of cytogenetic studies to select effective treatment options (e.g., acute myeloid leukemia). Thus, there may be important and distinct psychological considerations for a choroidal melanoma patient receiving prognostic information that currently does not inform treatment options.

To our knowledge, Cook et al. (2008) is the only group to have investigated whether choroidal melanoma patients want prognostic information. Their results indicate that the majority of choroidal melanoma patients do choose to receive prognostic information and do not report negative consequences as a result. However, their sample was
European, treated primarily with enucleation, and informed of their cytogenetic test result using survival estimates developed by their clinic (Damato et al. 2007); each of these parameters is different in the current study. As molecular-based prognostic information increasingly becomes the standard of care in choroidal melanoma, patients' opinions about and reactions to choroidal melanoma prognostic information must be studied in other clinical contexts.

Since January 2005, all choroidal melanoma patients having Iodine-125 plaque brachytherapy with intraoperative fine needle aspiration biopsy (FNAB) or enucleation at the Jules Stein Eye Institute have received results of cytogenetic testing as part of their care. Tumor prognostic testing is explained to patients at the time of diagnosis by the ophthalmic oncologist and by clinical staff. Patients are informed that they will be given one of three cytogenetic test results following surgery: (1) monosomy 3 , indicating that they are at higher risk for metastatic disease than if they received a disomy 3 result; (2) disomy 3, indicating a lower risk for metastatic disease than if they had received a monosomy 3 result; or (3) no chromosome 3 cytogenetic result due to an inconclusive tumor biopsy specimen. An inconclusive tumor specimen can occur because of small tumor size (i.e., not enough tumor tissue is gathered during biopsy) or because tumor tissue does not grow in culture (Young et al. 2007b); such results occur in 15-50\% of biopsy cases (Shields et al. 2007b; Young et al. 2007b). Care is taken when disseminating the results of this testing to refer only to relatively "higher" or "lower" metastatic risk and to emphasize that metastatic surveillance is on-going and not dependent upon test result. This approach is considerably more conservative than that taken by Cook et al. (2008) who recommend differences in surveillance based upon chromosome 3 result. Although survival estimates based on chromosome 3 status have been published (Prescher et al. 1996), these survival estimates are based on large tumors and may not be generalizable to the majority of our patients who have smaller tumors. We, therefore, do not give percentagebased survival estimates, as we feel this information is not definitively known at this time.

The goals of this study were the following: (1) to assess preference for receiving a prognostic cytogenetic test result in a sample of choroidal melanoma patients who both did and did not undergo cytogenetic testing; (2) to assess the perceived usefulness of cytogenetic test information in those patients who did undergo testing; (3) to understand patient-reported reasons for wanting (or not wanting) cytogenetic testing; (4) to understand how patients use their cytogenetic test result; and (5) in the sub-sample who received cytogenetic testing, to compare patients' depressive symptoms and quality of life based on the result of the cytogenetic test. 


\section{Methods}

Participants

Participants were patients who had consultation for choroidal melanoma at the Ophthalmic Oncology Center at the Jules Stein Eye Institute, University of California, Los Angeles, between January 1, 2002 and December 31, 2006. Patients were identified through medical records. Eligibility criteria required that participants live in the United States and be able to read and write in English. Study procedures and materials were approved by the UCLA Institutional Review Board and were compliant with the Health Insurance Portability and Accountability Act of 1996.

\section{Procedure}

Potential participants were mailed an introductory letter, consent form, questionnaire packet, and pre-paid return envelope. Questionnaires were distributed between the months of June 2006 and January 2007 as the first installment of a 6-month longitudinal study. The introductory letter explained that patients had been identified through medical records for possible inclusion in a study designed to examine the psychological impact of ocular melanoma. Patients were asked to complete and return by mail the informed consent form and study questionnaire. One to 3 weeks after packet mailings, research staff contacted potential participants by phone to confirm packet receipt and answer questions. If the phone call was not answered, research staff left a message informing patients that they would receive an invitation to participate in a study by researchers at the Jules Stein Eye Institute. Participants who did not respond within 8 weeks were sent a second identical questionnaire packet.

\section{Measures}

Demographic characteristics of age, education, ethnicity, occupation, work status, income, relationship status, and parental status were assessed. Depressive symptoms were assessed with the 20-item Center for Epidemiologic Studies-Depression Scale (Radloff 1977), on which higher scores indicate more depressive symptoms. Quality of life was evaluated with the RAND 36-Item Health Survey (MOS-SF-36; Ware and Sherbourne 1992; Ware and Gandek 1994; Ware et al. 1993), which contains 36 items and yields two summary scores: the Mental Component Summary and the Physical Component Summary. Higher scores indicate better quality of life. Cytogenetic testing preferences and opinions were assessed with authorconstructed items. Given that many of the participants did not have access to prognostic testing at the time of their diagnosis and treatment, a description of this test was provided:

"Due to new medical advances, a biopsy can now be performed on choroidal melanoma to determine a patient's risk for metastatic spread of the cancer to other areas of the body. If the tumor biopsy indicates a loss of one chromosome 3 (monosomy 3), the chance of future metastatic disease is higher than the risk in patients without monosomy 3. Although this information is now available for patients currently diagnosed with choroidal melanoma, it does not change treatment options at this time. Please answer the following questions regarding how useful you think this information might be."

Following this description, all patients, regardless of whether they had prognostic testing as part of their treatment, were asked the following questions: (1) "At the time of your treatment for choroidal melanoma, would you have wanted information about your prognosis (i.e., risk for the cancer spreading)?"; (2) (in regard to the previous question) "Why or why not?"; (3) "In giving this [prognostic] information to patients should supportive counseling be offered?".

A coding scheme was developed to describe themes in patients' written responses to "why or why not" they would have wanted prognostic test information (i.e., question \#2), which yielded 7 themes. Patient responses indicating a desire for prognostic test results were given any combination of the following codes: 1) information, 2) planning for self, 3) planning for others, 4) enhanced life appreciation, 5) other. Patient responses indicating that they did not want these results were given any combination of the following two codes: 6) focused on the current stressor of ocular melanoma, 7) focused on another medical stressor. Two trained research assistants coded each response. Inter-rater agreement was $88.9 \%$; of 359 total codes there were 40 discrepancies. A third independent coder decided discrepancies.

The final questions were directed toward patients who underwent prognostic testing as part of their clinical care: (4) "If you are a patient who has been treated very recently, your chromosome 3 information may have been given to you. Have you received this information?"; (5) "How useful were these results to you?" (response options ranged from "not at all useful" to "extremely useful"); (6) "Please describe briefly HOW this information has been useful to you".

A coding scheme containing 6 content categories was developed to quantify the written responses to the last question (i.e, \#6): (1) encouraged communication with doctor and/or family, (2) relief/hope, (3) inspired better health practices, (4) inspired emotional and/or practical preparation for a foreshortened future, (5) received no useful information because biopsy was inconclusive, (6) 
other. Inter-rater agreement between two coders was $95.0 \%$; of 60 possible codes there were 3 discrepancies. A third independent coder decided discrepancies.

\section{Statistical Analyses}

Descriptive statistics were generated for demographic information and reported as frequencies and percentages. Demographic variables were compared between patients who had undergone prognostic testing versus those who had not, using $t$-tests and Fisher's exact test where appropriate. Cytogenetic test classification was based upon medical record review. The number and percentage of participants reporting a desire for cytogenetic test information and stating that counseling should be offered when genetic test results are given were calculated. The number and percentage of participants reporting that they had received results and had found results useful were calculated. Depressive symptoms (CES-D) and mental and physical quality of life (MOS-SF-36) were compared between patients as a function of cytogenetic test result (i.e., disomy 3 , monosomy 3 , or inconclusive result) using analysis of variance (ANOVA). When a significant difference between the three groups was detected, separate pairwise comparisons (i.e., Fisher's exact test) were conducted between groups.

\section{Results}

Questionnaires were distributed to 224 patients; of these 53 (24\%) patients were ineligible for participation due to: death (14), inaccurate address (26), inability to speak English (6), incorrect diagnosis or diagnosis duration (6), or the return of an unidentifiable questionnaire (i.e., no name or consent form) (1). Of the remaining 171 packets, $99(58 \%)$ were completed and returned. Two participants requested assistance completing the questionnaire packet due to vision problems; research staff read the questionnaire over the telephone and collected verbal responses. Because the majority of patients who did not participate were not reached by phone, the reasons for nonparticipation were unknown. As choroidal melanoma has a 5-year all-cause mortality rate of approximately $20 \%$ and affects a relatively elderly population, it is possible that some non-respondents were deceased or too ill to participate. The average age of non-respondents (64 years of age) did not differ from the average age of those who responded (64 years of age). A greater proportion of non-respondents were male $(n=41$; $59 \%)$ than female $(n=29 ; 41 \%)$.

Demographics for the study sample are given in Table 1. Approximately equal numbers of men and women participated, but significantly more men underwent cytogenetic testing than did women. Patients undergoing cytogenetic testing had undergone treatment more recently and had significantly lower incomes than did patients who did not undergo cytogenetic testing. No other significant differences in demographic characteristics emerged between patients who did or did not undergo cytogenetic testing.

Table 2 displays responses to questions regarding cytogenetic testing. The percentage of the total sample giving each response is followed by cytogenetic subgroup (i.e., no testing, monosomy 3 , disomy 3 , or inconclusive result) response percentages. Table 2 indicates that 38 (38\%) patients in the sample underwent prognostic testing; of these, $11(29 \%)$ were monosomy 3, 13 (34\%) were disomy 3 , and $14(37 \%)$ received an inconclusive test result.

Ninety-six patients responded to the question regarding desire for prognostic information (i.e., cytogenetic test results); 93 (97\%) of these patients reported that they wanted this information. Furthermore, all participants who had undergone cytogenetic testing and received a result of monosomy 3 or disomy 3 who responded to this item reported that they had wanted prognostic information. Of the 92 patients who responded to the question assessing attitude toward counseling, 90 patients $(98 \%)$ reported that counseling should be offered at the time of receiving prognostic information. There were no significant differences in these results based on whether patients had or had not undergone testing.

Responses relevant to patients who underwent prognostic testing are presented in Table 3 . Nineteen of the 38 patients $(50 \%)$ who underwent prognostic testing reported that they had been informed of their prognostic test result. Significantly more patients receiving a result of either monosomy 3 or disomy 3 reported receiving their result than patients who had received an inconclusive result. The majority of participants $(58 \% ; n=14$ of 24$)$ who underwent prognostic testing and received a conclusive result (i.e., monosomy 3 or disomy 3 ), reported that chromosome 3 information had been useful to them. None of the patients who received an inconclusive result reported that the test had been useful. There was a significant difference in the perceived usefulness of cytogenetic testing results based upon the test result received $(p<.01)$; significantly more patients who received a disomy 3 result endorsed the usefulness of the test than patients who received a result of monosomy $3(p=.018)$ or inconclusive result $(p<.01)$ and significantly more patients who received a monosomy 3 result endorsed the usefulness of the test than patients who received an inconclusive result $(p=.028)$.

Twelve participants who had undergone genetic testing and received a result responded to the question of how prognostic information had been useful to them (monosomy 3: $n=6$, disomy 3: $n=5$, inconclusive result: $n=1$; Table 4). "Relief/hope" and "inspired emotional and/or practical 
Table 1 Baseline Characteristics of Choroidal Melanoma Patients $(n=99)$

\begin{tabular}{|c|c|c|c|c|}
\hline & $\begin{array}{l}\text { Total } \\
n=99 \\
\%(n)\end{array}$ & $\begin{array}{l}\text { Cytogenetic testing } \\
n=38 \\
\%(n)\end{array}$ & $\begin{array}{l}\text { Testing no cytogenetic } \\
n=61 \\
\%(n)\end{array}$ & $p$ value \\
\hline \multicolumn{5}{|l|}{ Sex } \\
\hline $\begin{array}{l}\text { Male } \\
\text { Female }\end{array}$ & $\begin{array}{l}51.5(51) \\
48.5\end{array}$ & $\begin{array}{l}71.1(27) \\
28.9(11)\end{array}$ & $\begin{array}{l}39.3(24) \\
60.7(37)\end{array}$ & $0.00 *$ \\
\hline \multicolumn{5}{|l|}{ Age at baseline ${ }^{a}$} \\
\hline $\begin{array}{l}20-39 \\
40-49 \\
50-59 \\
60-89\end{array}$ & $\begin{array}{c}5.1(5) \\
7.1(7) \\
20.2(20) \\
67.7(67)\end{array}$ & $\begin{array}{r}7.9(3) \\
10.5(4) \\
13.2(5) \\
68.4(26)\end{array}$ & $\begin{array}{c}3.3(2) \\
4.9(3) \\
24.6(15) \\
67.2(41)\end{array}$ & 0.31 \\
\hline \multicolumn{5}{|l|}{ Race } \\
\hline $\begin{array}{l}\text { White } \\
\text { Non white }\end{array}$ & $\begin{array}{l}85.9(85) \\
14.1(14)\end{array}$ & $\begin{array}{l}81.6(31) \\
18.4(7)\end{array}$ & $\begin{array}{l}88.5(54) \\
11.5(7)\end{array}$ & 0.33 \\
\hline \multicolumn{5}{|l|}{ Relationship status } \\
\hline $\begin{array}{l}\text { Married/committed } \\
\text { Not committed }\end{array}$ & $\begin{array}{l}66.7(64) \\
33.3(32)\end{array}$ & $\begin{array}{l}76.3(29) \\
23.7(9)\end{array}$ & $\begin{array}{l}60.3(35) \\
39.7(23)\end{array}$ & 0.10 \\
\hline \multicolumn{5}{|l|}{ Education } \\
\hline $\begin{array}{l}\text { College degree } \\
\text { No college degree }\end{array}$ & $\begin{array}{l}47.3(44) \\
52.7(49)\end{array}$ & $\begin{array}{l}51.4(19) \\
48.6(18)\end{array}$ & $\begin{array}{l}44.6(25) \\
55.4(31)\end{array}$ & 0.53 \\
\hline \multicolumn{5}{|c|}{ Annual household income } \\
\hline $\begin{array}{l}\$ 75 \mathrm{~K}+ \\
<\$ 75 \mathrm{~K}\end{array}$ & $\begin{array}{l}45.9(34) \\
54.1(40)\end{array}$ & $\begin{array}{l}29.6(8) \\
70.4(19)\end{array}$ & $\begin{array}{l}55.3(26) \\
44.7(21)\end{array}$ & $0.03 * *$ \\
\hline \multicolumn{5}{|l|}{ Treatment type } \\
\hline $\begin{array}{l}\text { Enucleation } \\
\text { Plaque radiotherapy } \\
\text { Proton beam therapy }\end{array}$ & $\begin{array}{c}16.3(16) \\
80.6(79) \\
3.1(3)\end{array}$ & $\begin{array}{c}10.5(4) \\
89.5(34) \\
0.0(0)\end{array}$ & $\begin{array}{c}16.0(12) \\
80.0(46) \\
4.0(3)\end{array}$ & 0.20 \\
\hline \multicolumn{5}{|l|}{ Employment status } \\
\hline $\begin{array}{l}\text { Yes } \\
\text { No }\end{array}$ & $\begin{array}{l}52.6(50) \\
47.4(45)\end{array}$ & $\begin{array}{l}47.4(18) \\
52.6(20)\end{array}$ & $\begin{array}{l}56.1(32) \\
43.9(25)\end{array}$ & 0.40 \\
\hline \multicolumn{5}{|l|}{ Children } \\
\hline $\begin{array}{l}\text { Yes } \\
\text { No }\end{array}$ & $\begin{array}{l}78.9(75) \\
21.1(20)\end{array}$ & $\begin{array}{l}77.1(27) \\
22.9(8)\end{array}$ & $\begin{array}{l}80.0(48) \\
20.0(12)\end{array}$ & 0.74 \\
\hline \multicolumn{5}{|l|}{ Months since diagnosis ${ }^{\mathrm{b}}$} \\
\hline Mean (std) & $24.8(17.8)$ & $7.1(4.5)$ & $34.9(14.2)$ & $0.00 *$ \\
\hline
\end{tabular}

preparation for a foreshortened future" were the two most frequently endorsed uses of genetic information (i.e., $n=5$; $41.7 \%$ for each response). An example of a verbatim response coded as "relief/hope" was "put my mind at ease" and an example coded as "inspired emotional and/or practical preparation" was "It has helped me prepare myself for the likely spread of my cancer and encouraged me to consider how I would change my life in the event of that spread". Significantly more disomy 3 participants produced written responses coded as "relief/hope" whereas significantly more monosomy 3 participants produced written responses coded as "inspired emotional and/or practical preparation for a foreshortened future" (Table 4). Less frequently endorsed reasons were "inspired better health practices" ( $n=1 ; 8.3 \%)$, "received no useful information because biopsy was inconclusive" $(n=1 ; 8.3 \%)$, and "other" $(n=1 ; 8.3 \%)$. No significant differences in depressive symptoms, mental health-related quality of life, or physical health-related quality of life were detected among the three groups that underwent prognostic testing.

Of the total sample, 73 (73\%) participants responded to a question regarding "why or why not" they would have wanted prognostic information at the time of diagnosis. There were no significant differences in responses as a function of having undergone cytogenetic testing or as a function of cytogenetic test result. Of the 73 participants, 47 (64\%) reported that a desire for information was a reason for wanting prognostic results, $33(45 \%)$ and $4(5 \%)$ of the responses indicated that prognostic information was desired for its use in planning for the patient and/or for others, respectively. Two patients (3\%) responded that knowledge of their prognosis would enhance their appreciation for life, and 5 patients $(7 \%)$ gave reasons coded as "other". Of the three participants who did not desire prognostic informa- 
Table 2 Patient Responses to Prognostic Testing Questions, Mean Depressive Symptoms, and Mean Quality of Life Scores Stratified by Cytogenetic Test Result

\begin{tabular}{|c|c|c|c|c|c|c|c|}
\hline \multirow[t]{2}{*}{$\begin{array}{l}\text { Questionnaire } \\
\text { item/scale }\end{array}$} & \multirow[t]{2}{*}{ Response } & \multicolumn{5}{|c|}{$\begin{array}{l}\text { Response by } \\
\text { category }\end{array}$} & \multirow[t]{2}{*}{$p$ value $^{\mathrm{a}}$} \\
\hline & & $\begin{array}{l}\text { Total } \\
(N=99) \\
\%(n)\end{array}$ & $\begin{array}{l}\text { No testing } \\
\quad(n=61) \\
\%(n)\end{array}$ & $\begin{array}{l}\text { Monosomy } 3 \\
\quad(n=11) \\
\%(n)\end{array}$ & $\begin{array}{l}\text { Disomy } 3 \\
(n=13) \\
\%(n)\end{array}$ & $\begin{array}{l}\text { Inconclusive } \\
\text { result }(n=14) \\
\%(n)\end{array}$ & \\
\hline \multirow[t]{2}{*}{$\begin{array}{l}\text { Patient-reported desire for } \\
\text { prognostic information }^{\mathrm{b}}\end{array}$} & $\begin{array}{l}\text { Yes } \\
\text { No }\end{array}$ & $\begin{array}{l}94 \%(93) \\
3 \%(3)\end{array}$ & $\begin{array}{l}93 \%(57) \\
3 \%(2)\end{array}$ & $\begin{array}{l}91 \%(10) \\
0 \%(0)\end{array}$ & $\begin{array}{l}100 \%(13) \\
0 \%(0)\end{array}$ & $\begin{array}{l}93 \%(13) \\
7 \%(1)\end{array}$ & \multirow[t]{2}{*}{0.99} \\
\hline & No response & $3 \%(3)$ & $3 \%(2)$ & $9 \%(1)$ & $0 \%(0)$ & $0 \%(0)$ & \\
\hline \multirow[t]{2}{*}{$\begin{array}{l}\text { Patient-reported desire for } \\
\text { supportive counseling }\end{array}$} & $\begin{array}{l}\text { Yes } \\
\text { No }\end{array}$ & $\begin{array}{l}91 \%(90) \\
2 \%(2)\end{array}$ & $\begin{array}{l}92 \%(56) \\
2 \%(1)\end{array}$ & $\begin{array}{l}91 \%(10) \\
0 \%(0)\end{array}$ & $\begin{array}{l}84 \%(11) \\
8 \%(1)\end{array}$ & $\begin{array}{l}93 \%(13) \\
0 \%(0)\end{array}$ & \multirow[t]{2}{*}{0.44} \\
\hline & No Response & $7 \%(7)$ & $7 \%(4)$ & $9 \%(1)$ & $8 \%(1)$ & $7 \%(1)$ & \\
\hline $\begin{array}{l}\text { Depressive symptoms } \\
(\text { CES-D })^{\mathrm{c}}\end{array}$ & & $\begin{array}{l}M=7.7 \\
\mathrm{SD}=1.6\end{array}$ & $\begin{array}{l}M=7.6 \\
\mathrm{SD}=2\end{array}$ & $\begin{array}{l}M=3.7 \\
\mathrm{SD}=1.2\end{array}$ & $\begin{array}{l}M=9.7 \\
\mathrm{SD}=6.2\end{array}$ & $\begin{array}{l}M=9.5 \\
\mathrm{SD}=6.2\end{array}$ & $\begin{array}{l}F=1.72 \\
p=0.19\end{array}$ \\
\hline $\begin{array}{l}\text { Mental Health Component } \\
\text { Summary Score } \\
(\text { MOS-SF-36) }\end{array}$ & & $\begin{array}{l}M=52.7 \\
\mathrm{SD}=2\end{array}$ & $\begin{array}{l}M=53.9 \\
\mathrm{SD}=2.3\end{array}$ & $\begin{array}{l}M=53.2 \\
\mathrm{SD}=2.4\end{array}$ & $\begin{array}{l}M=47.7 \\
\mathrm{SD}=7.9\end{array}$ & $\begin{array}{l}M=52.0 \\
\mathrm{SD}=6.9\end{array}$ & $\begin{array}{l}F=0.82 \\
p=0.45\end{array}$ \\
\hline $\begin{array}{l}\text { Physical Health Component } \\
\text { Summary Score } \\
\text { (MOS-SF-36) }^{c}\end{array}$ & & $\begin{array}{l}M=44.9 \\
\mathrm{SD}=2.3\end{array}$ & $\begin{array}{l}M=44.0 \\
\mathrm{SD}=3.2\end{array}$ & $\begin{array}{l}M=45.2 \\
\mathrm{SD}=4\end{array}$ & $\begin{array}{l}M=49.9 \\
\mathrm{SD}=6\end{array}$ & $\begin{array}{l}M=43.8 \\
\mathrm{SD}=7.4\end{array}$ & $\begin{array}{l}F=1.24 \\
p=0.30\end{array}$ \\
\hline
\end{tabular}

${ }^{*} p<0.01$

${ }^{a} p$ value is based only on individuals tested who also responded to the relevant questionnaire item

${ }^{\mathrm{b}}$ Chi-square test

${ }^{\mathrm{c}} T$ test

tion, two gave reasons for this preference. The first patient cited other medical problems as the reason, but indicated that he or she would have wanted the information at a later time; the second patient reported that he or she was focused on the current stressor of ocular melanoma. There were no significant differences in responses based upon whether patients did or did not undergo testing nor were there differences as a function of the specific result the patient received.

\section{Discussion}

Molecular prognostic testing in choroidal melanoma is distinct from prognostic testing in other cancers. The patient who may receive prognostic testing has already been diagnosed with a malignancy, and the test provides information regarding risk of metastasis, which is almost always fatal and which has no accepted or effective pre-metastatic treatment protocol. This is in

Table 3 Information Specific to Patients Who Received Chromosome 3 Testing and Results $(N=38)$

\begin{tabular}{|c|c|c|c|c|c|c|}
\hline Questionnaire item & Response & $\begin{array}{l}\text { Total } \\
(N=38) \\
\%(n)\end{array}$ & $\begin{array}{l}\text { Monosomy } 3 \\
(n=11) \\
\%(n)\end{array}$ & $\begin{array}{l}\text { Disomy } 3 \\
(n=13) \\
\%(n)\end{array}$ & $\begin{array}{l}\text { Inconclusive result } \\
(n=14) \\
\%(n)\end{array}$ & $p$ value $^{\mathrm{a}}$ \\
\hline \multirow{3}{*}{$\begin{array}{l}\text { Patient-reported receipt } \\
\text { of chromosome } \\
3 \text { information }\end{array}$} & Yes & $50 \%(19)$ & $73 \%(8)$ & $69 \%(9)$ & $14 \%(2)$ & \multirow[t]{3}{*}{$0.00 *$} \\
\hline & No & $50 \%(19)$ & $27 \%(3)$ & $31 \%(4)$ & $86 \%(12)$ & \\
\hline & No Response & $0 \%(0)$ & $0 \%(0)$ & $0 \%(0)$ & $0 \%(0)$ & \\
\hline \multirow{3}{*}{$\begin{array}{l}\text { Patient-reported } \\
\text { usefulness of chromosome } \\
3 \text { information }{ }^{\mathrm{b}}\end{array}$} & Useful $^{\mathrm{c}}$ & $37 \%(14)$ & $46 \%(5)$ & $69 \%(9)$ & $0 \%(0)$ & \multirow[t]{3}{*}{$0.00^{*}$} \\
\hline & Not useful $^{\mathrm{d}}$ & $18 \%(7)$ & $18 \%(2)$ & $0 \%(0)$ & $36 \%(5)$ & \\
\hline & No response & $45 \%(17)$ & $36 \%(4)$ & $31 \%(4)$ & $64 \%(9)$ & \\
\hline
\end{tabular}

$* p<0.01$

${ }^{a} p$ value is based only on individuals tested who also responded to the relevant questionnaire item

${ }^{\mathrm{b}}$ Chi-square test

${ }^{c}$ Responses included "a little useful", "useful", "extremely useful"

${ }^{\mathrm{d}}$ Responses included "not at all useful", "not sure or do not know" 
Table 4 Comparison of Written Responses to the Question "Please Describe Briefly How this Information Has Been Useful to You" by Cytogenetic Test Result Received

\begin{tabular}{|c|c|c|c|c|}
\hline \multirow[b]{2}{*}{ Content area } & \multicolumn{3}{|c|}{$\begin{array}{l}\text { Percentage of written responses } \\
\text { reflecting each content area }\end{array}$} & \multirow[b]{2}{*}{$p$ value } \\
\hline & $\begin{array}{l}\text { Monosomy } 3 \\
(n=6) \\
\%(n)\end{array}$ & $\begin{array}{l}\text { Disomy } 3 \\
(n=5) \\
\%(n)\end{array}$ & $\begin{array}{l}\text { Inconclusive Result } \\
(n=1) \\
\%(n)\end{array}$ & \\
\hline 1. Encouraged communication with doctor and/or family & $0(0)$ & $0(0)$ & $0(0)$ & NA \\
\hline 2. Relief/hope & $0(0)$ & $100(5)$ & $0(0)$ & $0.00 * *$ \\
\hline 3. Inspired better health practices & $0(0)$ & $20(1)$ & $0(0)$ & 0.50 \\
\hline 4. Inspired emotional and/or practical preparation for a foreshortened future & $83(5)$ & $0(0)$ & $0(0)$ & $0.02 *$ \\
\hline 5. Received no useful information because biopsy was inconclusive & $0(0)$ & $0(0)$ & $100(1)$ & 0.08 \\
\hline 6. Other & $17(1)$ & $0(0)$ & $0(0)$ & 0.99 \\
\hline
\end{tabular}

${ }^{*} p<0.05 ; * * p<0.01$

contrast to genetic testing in breast cancer (BRCA1/2), for instance, for which a patient can be tested prior to being affected and for which effective risk reduction strategies are established (i.e., chemoprevention and/or prophylactic surgery). In addition, there is no consensus on the most accurate prognostic test to use for choroidal melanoma metastatic prognostication at this time. At our institution, patients who receive a monosomy 3 or disomy 3 result of their tumor biopsy are told that they are at higher or lower metastatic risk relative to the other result group. Follow-up ocular care and periodic investigations for metastatic surveillance do not differ between these groups of patients. Because the cytogenetic prognostic status of the tumor does not influence medical management at this time, it is important to know whether and why patients want this information and whether they experience psychological detriment in the case of an unfavorable prognostic test result.

Nearly all participants, regardless of whether they underwent treatment for choroidal melanoma before or after the implementation of cytogenetic prognostic testing at the Jules Stein Eye Institute, indicated that they wanted prognostic information despite being informed that the result would not influence medical care. All responding participants who had undergone cytogenetic testing as part of their treatment and received a result of monosomy 3 or disomy 3 reported that they wanted this information. This indicated no obvious regret or dissatisfaction as a result of receiving this information. In fact, only 3 participants in the total sample reported that they did not want prognostic information, and one of these participants indicated that the result would have been desired later.

Prognostic testing in choroidal melanoma is a recent clinical development with no similar testing in other cancer populations. Because of this, the quality of life of our sample cannot be compared to an analogous group of patients. However, the average mental health $(M=52.7)$ and physical health $(M=44.9)$ quality of life scores of the total sample mirrored the average scores of an age-matched population sample (i.e., mental health $M=51.05$, physical health $M=45.9$ ), as well as those of another uveal melanoma sample reported by Cruickshanks and colleagues (mental health $M=54.8$, physical health $M=45.6$ ) with a similar age and gender distribution (1999). Furthermore, depressive symptoms and quality of life in psychological and physical domains did not differ significantly between patients who received a monosomy 3 , disomy 3 , or an inconclusive result. The average depressive symptom score among patients who received their prognostic test result (and those who did not) was well below 16, the accepted CES-D cut-off indicative of clinically meaningful depressive symptoms and, although not significant, the average depressive symptoms score was lower among individuals with a monosomy 3 result than among individuals with a disomy 3 or inconclusive result. The current sample was small and these results require replication in a larger sample, however, our findings suggest that individuals who receive an unfavorable test result do not report more psychological morbidity than patients who receive a favorable test result. Although the prognostic information given at our institute is less specific than that given by Cook et al. (2008), the results of both investigations indicate that patients want prognostic information and do not experience psychological morbidity as a result of receiving this information.

Regarding motivation for having a prognostic test, most of the patients in our sample indicated that they wanted the information to plan for the future. Cook et al. (2008) also found that patients wanted prognostic information to plan for the future; however, information gathered during a small 
group of interviews by Cook et al. following testing suggest that the primary benefits patients reported after receiving results were a sense of control and hopefulness that continuing medical research and surveillance would prolong their survival. In our study, many participants wrote that knowing prognostic information, even if it indicated a heightened risk of metastatic spread, reduced their uncertainty and its accompanying anxiety. Motivation for wanting prognostic test results in the absence of effective medical interventions is likely complicated and may change over time; longitudinal studies of how patients use their prognostic information would be informative.

The majority of participants who did learn their prognostic test result, not including those who received an inconclusive result, reported that the information had been useful to them. Thus, patients who received a definitive result reported benefits from having undergone testing regardless of the result. Patients who received a monosomy 3 result were most likely to report that they used their results to prepare, either emotionally or physically, for a foreshortened future whereas patients who received a disomy 3 result most often reported that the test was useful by giving them a sense of hope and/or relief. Notably, one individual with a monosomy 3 test result did not respond to the question of whether the information was useful to him or her; instead this individual wrote, "useful is the wrong word. I can't use the info, only acknowledge and participate in my every 6 month PET/CT". It is important for individuals involved in choroidal melanoma patient care to understand the differing motivations for and perceptions of prognostic testing and the implications they may have for patient behavior and psychological functioning.

Of interest, we found that not all patients who underwent prognostic testing reported having received their prognostic test result and that one patient recalled undergoing prognostic testing when they had not. These inconsistencies may indicate that patients either did not recall prognostic information, did not understand the information when it was given to them, or, particularly in the case of the patient who incorrectly recalled receiving a result, did not understand the intended meaning of the questionnaire item. It is not surprising that many patients who received an inconclusive result reported that they had not received a result. However, 7 of 24 patients whose tumor was characterized as monosomy 3 or disomy 3 reported that they had not received this information, despite this information being personally shared with the patient by the ophthalmic oncologist following surgery. Anxiety is known to impair health-information processing (Ben-Zur and Breznite 1997) and it is possible that patient anxiety may have interfered with comprehension of test results. Although our findings demonstrate that patients want prognostic information, this information may be difficult for some patients to comprehend and perhaps should be communicated on repeated occasions and through multiple channels. In response to this finding, we are developing a more detailed results dissemination protocol that includes printed materials and additional opportunities for physician and patient discussion surrounding prognostic results.

Nearly all choroidal melanoma patients reported that counseling should be offered at the time of receiving prognostic information. Counseling may provide both psychological support and clarification of patients' prognostic information, which may enhance the understanding of results. At our institution, counseling is provided by psychologists and social workers who specialize in oncology. These counselors have been educated about the medical implications of chromosome 3 testing by Jules Stein ophthalmic oncologists and discuss prognostic results with patients only after results have been given to patients by their ophthalmic oncologist. When possible, counselors speak with patients immediately after they are informed of their prognostic result as well as during subsequent visits with their ophthalmic oncologist. While the content of these meetings is individualized to meet the presenting needs of each patient and continues to evolve as research and practitioner experience identify common themes in choroidal melanoma patients' experience, the first meeting often includes support and clarification of results and suggestions for coping with uncertainty. Subsequent meetings often involve helping patients integrate the meaning of this information into the broader context of their lives and the results of the present research have been helpful in alerting clinicians to how tests results may be meaningful to patients. In our experience, there is a result acclimation period during which the personal meaning of the result changes; therefore, counseling should be offered throughout this process. Counselors with a background in genetic testing also would be suited to such work as they have experience explaining complicated risk information and providing psychological support related to this information.

A limitation of this study is that $42 \%$ of potential participants did not respond to the invitation to participate. Despite this, the response rate of 58\% was good for a mailformat, retrospective study and is slightly higher than the mean response rate of published surveys conducted by physicians (i.e, 54\%; Asch et al. 1997). Although it is likely that some non-respondents were ill or deceased, it is also possible that non-respondents' opinions about cytogenetic testing differ in a meaningful way from those who did participate. Another limitation is the retrospective nature of this study. It may be that opinions of previously treated patients differ from the opinions of patients who are prospectively considering the questions. Although findings might have been affected by retrospective recall bias and variability in length of time since ocular melanoma 
diagnosis, analyses demonstrated no significant relations between diagnosis duration and psychological status or responses regarding cytogenetic testing. Finally, as socioeconomic status has been shown to influence interest in (Dormandy et al. 2005) and reactions to genetic information (Charles et al. 2006), it is important to note that patients who underwent prognostic testing in this sample were less affluent than those who did not. Although there were no significant differences in psychological status between the two groups our sample size is small; whether and how such demographic characteristics affect individuals who undergo testing is an important question for future research.

In summary, this study demonstrates that patients with choroidal melanoma desire knowledge of prognostic test results and that concomitant counseling should be offered. Patients who had already received prognostic results reported that they were useful. Furthermore, no psychologically detrimental consequences of having undergone prognostic testing were detected. The study also suggests that prognostic results may be difficult to understand for some patients; the most effective way to disseminate these results requires further study. Finally, as cytogenetic testing for prognosis in choroidal melanoma evolves, continued research on how patients use and adjust psychologically to this information will be necessary.

Acknowledgments The authors wish to thank all of those who participated in this study as well as Lorna Kwan, MPH, Jonsson Comprehensive Cancer Center, for her statistical consultation and assistance. This research was supported by a Jonsson Comprehensive Cancer Center Pre-Doctoral Fellowship and a UCLA Graduate Division Dissertation Year Fellowship to Tammy M. Beran and by Jonsson Comprehensive Cancer Center funding to Annette L. Stanton.

Open Access This article is distributed under the terms of the Creative Commons Attribution Noncommercial License (https:// doi.org/creativecommons.org/licenses/by-nc/2.0/), which permits any noncommercial use, distribution, and reproduction in any medium, provided the original author(s) and source are credited.

\section{References}

Asch, D. A., Jedrziewski, M. K., \& Christakis, N. A. (1997). Response rates to mail surveys published in medical journals. Journal of Clinical Epidemiology, 50(10), 1129-1136.

Bedikian, A. Y. (2006). Metastatic uveal melanoma therapy: current options. International Ophthalmology Clinics, 46(1), 151-166.

Ben-Zur, H., \& Breznitz, S. (1997). Denial, anxiety and information processing. In M. S. Myslobodsky (Ed.), The mythomanias: The nature of deception and self-deception (pp. 225-243). Hillsdale: Lawrence Erlbaum.

Bird, S. J. (1989). Genetic testing for neurologic diseases: a rose with thorns. Neurologic Clinics, 7(4), 859-870.

Charles, S., Kessler, L., Stopfer, J. E., Domchek, S., \& Halbert, C. H. (2006). Satisfaction with genetic counseling for BRCA1 and BRCA2 mutations among African American women. Patient Education and Counseling, 63(1-2), 196-204.
Cook, S. A., Damato, B., Marshall, E., \& Salmon, P. (2008). Psychological aspects of cytogenetic testing of uveal melanoma: preliminary findings and directions for future research. Eye, advanced online publication doi:10.1038/eye2008.54.

Cruickshanks, K. J., Fryback, D. G., Nondahl, D. M., Robinson, N., Keesey, U., Dalton, D. S., et al. (1999). Treatment choice and quality of life in patients with choroidal melanoma. Archives of Ophthalmology, 117(4), 461-467.

Damato, B., Duke, C., Coupland, S. E., Hiscott, P., Smith, P. A., Campbell, I., et al. (2007). Cytogenetics of uveal melanoma: a seven-year clinical experience. Ophthalmology, 114(10), 19251931.

Dormandy, E., Michie, S., Hooper, R., \& Marteau, T. M. (2005). Low uptake of prenatal screening for Down syndrome in minority ethnic groups and socially deprived groups: a reflection of women's attitudes or a failure to facilitate informed choices? International Journal of Epidemiology, 34(2), 346-352.

Fertig, D. L., \& Hayes, D. F. (2001). Considerations in using tumor markers: what the psycho-oncologist needs to know. Psychooncology, 10(5), 370-379.

Harbour, J. W. (2007). Molecular prognostic testing in uveal melanoma: has it finally come of age? Archives of Ophthlmology, 125(8), 1122-1123.

Hawkins, B. S. (2004). The Collaborative Ocular Melanoma Study (COMS) randomized trial of pre-enucleation radiation of large choroidal melanoma: IV. Ten-year mortality findings and prognostic factors COMS report number 24. American Journal of Ophthalmology, 138(6), 936-951.

Kujala, E., Makitie, T., \& Kivela, T. (2003). Very long-term prognosis of patients with malignant uveal melanoma. Investigative Ophthalmology and Visual Science, 44(11), 4651-4659.

McLaughlin, C. C., Wu, X. C., Jemal, A., Martin, H. J., Roche, L. M., \& Chen, V. W. (2005). Incidence of noncutaneous melanomas in the U.S. Cancer, 103(5), 1000-1007.

Meiser, B. (2005). Psychological impact of genetic testing for cancer susceptibility: an update of the literature. Psychooncology, 14 (12), 1060-1074.

Midena, E., Bonaldi, L., Parrozzani, R., Tebaldi, E., Boccassini, B., \& Vujosevic, S. (2006). In vivo detection of monosomy 3 in eyes with medium-sized uveal melanoma using transscleral fine needle aspiration biopsy. European Journal of Ophthalmology, 16(3), 422-425.

Miki, Y., Swensen, J., Shattuck-Eidens, D., Futreal, P. A., Harshman, K., Tavtigian, S., et al. (1994). A strong candidate for the breast and ovarian cancer susceptibility gene BRCA1. Science, 266 (5182), 66-71.

Onken, M. D., Worley, L. A., Davila, R. M., Char, D. H., \& Harbour, J. W. (2006). Prognostic testing in uveal melanoma by transcriptomic profiling of fine needle biopsy specimens. The Journal of Molecular Diagnostics, 8(5), 567-573.

Prescher, G., Bornfeld, N., Hirche, H., Horsthemke, B., Jockel, K. H., \& Becher, R. (1996). Prognostic implications of monosomy 3 in uveal melanoma. Lancet, 347(9010), 1222-1225.

Radloff, L. (1977). The CES-D Scale: a self-report depression scale for research in the general population. Applied Psychological Measurement, 1(3), 385-401.

Robertson, D. M. (2008). Cytogenetics in the management of uveal melanoma: are we there yet? Archives of Ophthalmology, 126(3), 409-410.

Scholes, A. G., Damato, B. E., Nunn, J., Hiscott, P., Grierson, I., \& Field, J. K. (2003). Monosomy 3 in uveal melanoma: correlation with clinical and histologic predictors of survival. Investigative Ophthalmology and Visual Science, 44(3), 1008-1011.

Scotto, J., Fraumeni, J. F. Jr., \& Lee, J. A. (1976). Melanomas of the eye and other noncutaneous sites: epidemiologic aspects. Journal of the National Cancer Institute, 56(3), 489-491. 
Shields, C. L., Ganguly, A., Materin, M. A., Teixeira, L., Mashayekhi, A., Swanson, L. A., et al. (2007a). Chromosome 3 analysis of uveal melanoma using fine-needle aspiration biopsy at the time of plaque radiotherapy in 140 consecutive cases: the Deborah Iverson, MD, Lectureship. Archives of Ophthalmology, 125(8), $1017-1024$.

Shields, C. L., Materin, M. A., Teixeira, L., Mashayekhi, A., Ganguly, Al., \& Shields, J. A. (2007b). Small choroidal melanoma with chromosome 3 monosomy on fine-needle aspiration biopsy. Ophthalmology, 114(10), 1919-1924.

Shields, J. A., Shields, C. L., Materin, M., Sato, T., \& Ganguly, A. (2008). Role of cytogenetics in management of uveal melanoma. Archives of Ophthalmology, 126(3), 416-419.

Sisley, K., Rennie, I. G., Parsons, M. A., Jacques, K., Hammond, D. W., Bell, S. M., et al. (1997). Abnormalities of chromosomes 3 and 8 in posterior uveal melanoma correlate with prognosis. Genes, Chromosomes \& Cancer, 19(1), 22-28.

Tschentscher, F., Prescher, G., Zeschnigk, M., Horsthemke, B., \& Lohmann, D. R. (2000). Identification of chromosomes 3, 6, and 8 aberrations in uveal melanoma by microsatellite analysis in comparison to comparative genomic hybridization. Cancer Genetics and Cytogenetics, 122(1), 13-17.

Ware, J. E., \& Gandek, B. (1994). The SF-36 Health Survey: development and use in mental health research and the IQOLA Project. International Journal of Mental Health, 23(2), 49-73.
Ware, J., \& Sherbourne, C. (1992). The MOS 36-Item Short Form Health Survey (SF-36): conceptual framework and item selection. Medical Care, 30(6), 473-483.

Ware, J., Snow, K., Kosinski, M., \& Gandek, B. (1993). SF-36 health survey manual and interpretation guide. Boston: The Health Institute, New England Medical Center.

White, V. A., Chambers, J. D., Courtright, P. D., Chang, W. Y., \& Horsman, D. E. (1998). Correlation of cytogenetic abnormalities with the outcome of patients with uveal melanoma. Cancer, 83(2), 354-359.

Williams, J. K., Schutte, D. L., Evers, C., \& Forcucci, C. (1999). Adults seeking presymptomatic gene testing for Huntington disease. Image: Journal of Nursing Scholarship, 31(2), 109-114.

Wooster, R., Bignell, G., Lancaster, J., Swift, S., Seal, S., Mangion, J., et al. (1995). Identification of the breast cancer susceptibility gene BRCA2. Nature, 378(6567), 789-792.

Young, T. A., Burgess, B. L., Rao, N. P., Gorin, M. B., \& Straatsma, B. R. (2007a). High density genome array is superior to fluorescence insitu hybridization analysis of monosomy 3 in choroidal melanoma fine needle aspiration biopsy. Molecular Vision, 21(13), 23282333.

Young, T. A., Rao, N. P., Glasgow, B. J., Moral, J. N., \& Straatsma, B. R. (2007b). Fluorescent in situ hybridization for monosomy 3 via 30 -gauge fine-needle aspiration biopsy of choroidal melanoma in vivo. Ophthalmology, 114(1), 142-146. 